\title{
Research on the Optimization of Integrated Service Platform of Supply Chain Finance
}

\author{
Wei Xing \\ Hunan Vocational College of Modern Logistics, Changsha, China
}

Keywords: supply chain; finance platform; optimization

\begin{abstract}
With the rapid development of Internet finance, significant progress has been made in China's supply chain finance in terms of technology and efficiency. Traditional supply chain finance is dominated by financial institutions such as banks with advantages of capital and resource, but its development momentum is relatively insufficient. There are various problems in the supply chain finance platform, such as lack of compatibility of operating platforms, information asymmetry, risks and system security loopholes. From the perspective of optimizing the traditional supply chain financial platform, this paper integrates the characteristics of supply chain finance and the current problems in the supply chain financial platform to build an integrated service innovation service platform for supply chain finance as a way to create more financial service value to realize the true integration between industry and finance.
\end{abstract}

\section{Introduction}

Supply chain finance, firstly traced from the trade financing, has gone through four major periods: the bill discount (similar to the 1940s in the US), the trade finance, the initial development of supply chain finance, and the full development of supply chain finance (with online as a prominent feature). [1]China's supply chain finance was first proposed by the Shenzhen Development Bank in 2006; in July 2010, Industrial and Commercial Bank of China (ICBC) launched an online supply chain financial service platform; soon afterwards, China Construction Bank and Bank of China also launched the business of supply chain finance. [2] The main domestic related research: supply chain finance, mainly based on commercial banks, is essentially the trade financing service based on prepayments, receivable accounts and inventory (Xie Shiqing et al., 2013). [3] It is a service model to improve the operation of the supply chain (Xu Xianhao et al., 2011). [4] Supply chain finance, characterized by reducing trade costs (Jiang Wei, Yao Wentao, 2016) and improving financing efficiency (Yang Bin et al., 2016), has gradually become an important model for financing of modern enterprises, especially small and medium-sized enterprises, which can effectively alleviate the financing constraints of SMEs (Zhang Weibin, Liu Ke, 2012). [5] As a financial business model with long development history, supply chain finance, unmatured in practical operation, does not fully release its potential.

\section{Overview of Supply Chain Finance}

\subsection{Concept of Supply Chain Finance}

Briefly speaking, supply chain finance is a financing model in which banks associate core businesses with upstream and downstream companies to provide financial products and services with flexible use. In other words, financial institutions, centering on core enterprises, manage the capital flow and logistics of upstream and downstream SMEs through certain means and tools. It is the financial service which obtains comprehensively the production and sales information of upstream and downstream companies with core enterprises as their center for, transforms the uncontrollable risks of individual companies to the controllable risks of the supply chain enterprises and controls the risk to the lowest. As shown in Figure 1. 


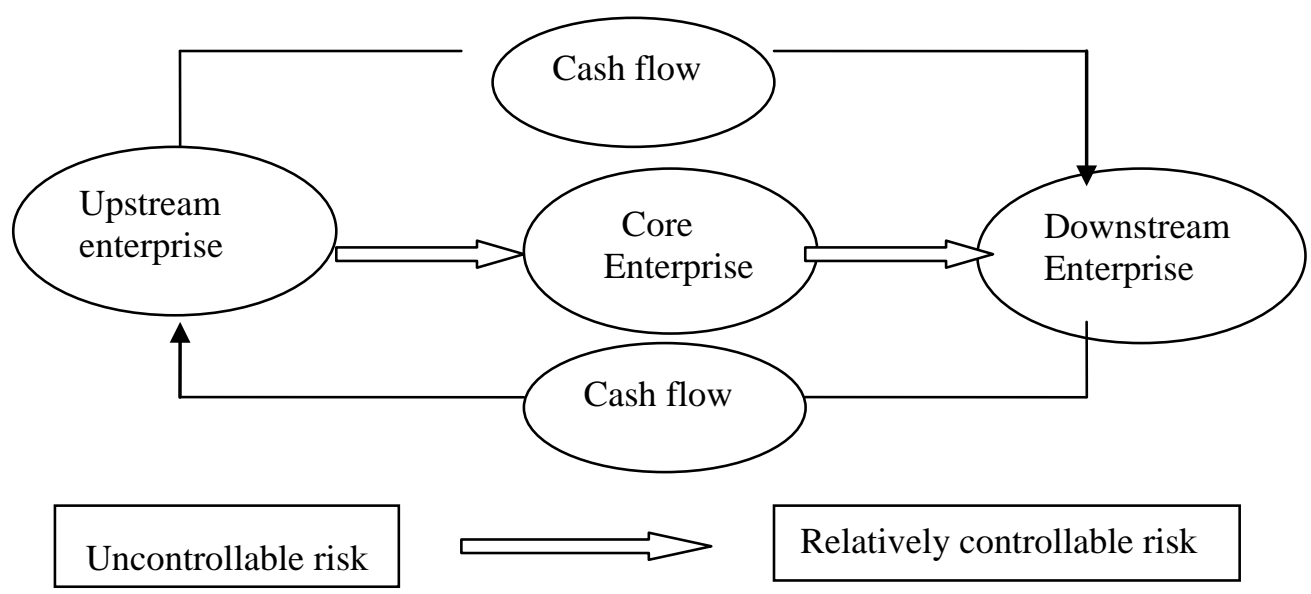

Figure 1 Risk Chart of Supply Chain Finance

\subsection{Types of Supply Chain Finance}

Simply speaking, China's supply chain finance can be divided into two categories: traditional supply chain finance and modern new supply chain finance. Traditional supply chain finance is dominated by traditional financial institutions, such as banks. Take the bank as an example, the bank as a leading partner works closely with the core enterprise, third-party logistics and warehousing agencies to confirm the credit of upstream and downstream enterprises in the industry chain, monitor the inventory of financing groups, and master receivable accounts information, and rely on the endorsement of the core enterprise's credit to provide financial services for its upstream and downstream companies as a way to effectively reduce bank credit risks. The new supply chain, dominated by core enterprises, plays a dominant role in the industrial supply chain and relies on a full understanding of upstream and downstream companies to provide financial services to the proposed financing company. The new supply chain finance mainly includes the group dominant model and the platform dominant model. The group-dominated model refers to that the enterprise group controls financial institutions or selects external financial institutions to provide financing services for enterprises in its industrial chain. This model is generally carried out by an enterprise group that has both industrial and financial resource advantages. The platform-dominated supply chain finance enjoys advantages in terms of a certain number. The third-party organizations usually rely on their own technology and information advantages through the Internet platform to carries out supply chain finance business. The platform-led supply chain finance enjoys high level online finance, abundant data resources, relatively advanced risk control technology, and the key lies in relying on the technological advantage to enter the field of supply chain finance.

\section{Problems in Supply Chain Finance Platform}

\subsection{Lack of Compatibility for Operating Platform}

Online supply chain financial services require the enterprise's ERP and logistics system to interface with the bank's supply chain financial platform to achieve real-time data interaction. However, the data interfaces of different enterprises are often inconsistent, and it is difficult to be compatible. At present, most domestic supply chain financial systems, basically independent operating systems within the enterprise enjoy low degree of internalization, which greatly reduces the operational efficiency of supply chain finance.

\subsection{Information Asymmetry}

Since the shared information of the supply chain is extracted or integrated by the internal information systems of the enterprises, each node enterprise may hide some information that involves trade secrets or may be risky or fake data to defraud lines of credit for the sake of interest, thus creating moral hazard. 


\section{Major Risks and Issues of System Security}

Currently, online supply chain finance business still belongs to emerging product services, and there are still numerous risks, such as credit risk of supply chain entities, risks arising from the authenticity of trading trade and from business operations, risks of logistics regulators, and the value risk of assets pledged. On the other hand, since online supply chain finance are based on electronic operations, transaction content, account information and customer data will all be transmitted on the Internet, so there are system security risks such as information disclosure, unauthorized tampering, and hacker attack and theft. On the other hand, as online supply chain financial system involves the financial, logistics and storage system of enterprises, any mistake, delay or breakdown of system will lead to errors in the supply chain financial platform system and even do harm to other related bank information systems.

\section{Construction of Optimization Model of Integrated Service Platform of Supply Chain Finance}

This platform is an integrated service innovation platform for supply chain finance designed to solve the problems existing in China's traditional supply chain finance platform and based on the risk of the traditional supply chain financial platform, as shown in Figure 2.

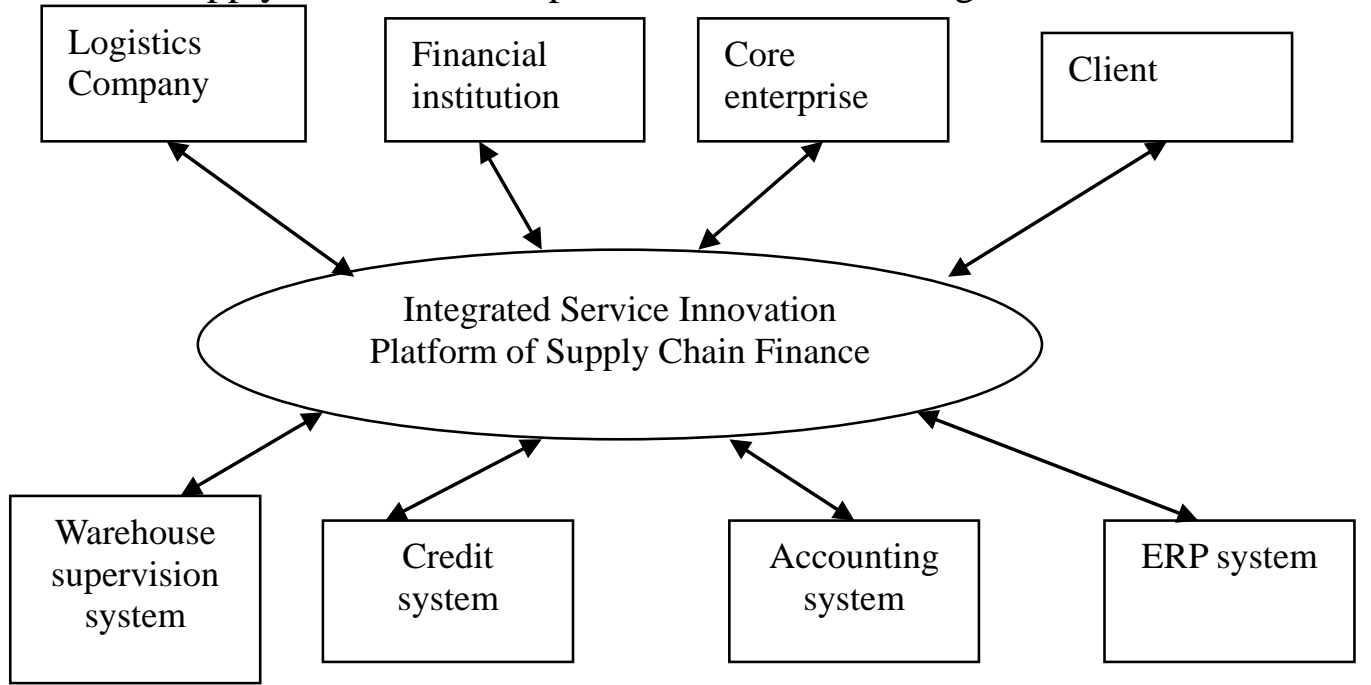

Figure 2 Integrated Services Innovation Platform of Supply Chain Finance

\subsection{Select Quality Customers}

\subsubsection{Strictly Control Customer Access}

Core enterprises formulate specific "customer access standards" based on years of cooperation and recommend quality customers to financial institutions

\subsubsection{Customers Choose to Include Financial Institutions to Accept Unified Credit Management}

Firstly, the credit department audits customer qualifications, includes credit management, and conducts pre-lending investigations. The investigation includes: the customer's production and operation, organization structure, and actual controller; whether the license is complete, the business is stable, and the credit is good. Secondly, the Risk Control Compliance Department conducts risk control review that contains risk analysis of various risks of customer production and operations, and further risk assessment of customer qualifications.

\subsection{Reduce Information Asymmetry Risk}

The supply chain financing business platform is established to form an Internet-based operating platform. The core enterprise internal management system such as ERP, logistics and warehousing 
supervision system, financial institution credit and accounting processing system are successfully docked to convert the logistics and information flow related to supply chain finance business into capital flow by "supply chain financing business platform". Then, 24-hour monitoring of collateral movement information, including the quantity, quality, market price fluctuations is conducted to effectively guarantee "safety stocks" through "supply chain financing business platform”.

\subsection{Reduce Operational Risk}

\subsubsection{Formulating Operating Manuals and Risk Control Systems}

Formulate business operations manuals and corresponding risk control systems in accordance with various supply chain financial services. The key points of each link in the supply chain financing business process are regulated accordingly.

\subsubsection{Realizing the Whole Process Risk Control of the Business by Information Platform}

Build a full-process information system that covers the supply chain finance business, and establish an information-based control mechanism for each risk point in the financial business process.

\subsection{Create the Professional Finance Team}

\subsubsection{Establishing Excellency Selection Mechanism.}

Establish an "open, fair, and just” mechanism for selecting and employing people. The strict standards should be established in terms of selecting and employing team personnel who have strong continuous learning ability and boasts strong comprehensive ability in terms of the financial analysis, industrial chain, logistics supervision, legal prevention and control.

\subsubsection{Establishing Scientific and Reasonable Incentive Mechanism.}

Incentives include material rewards and spiritual incentives. Various learning and training opportunities are provided through the planning of career advancement and professional career design so that each member can clearly recognize their own ways of growth, be passionate about their work, and be full of hope.

\subsubsection{Cultivating Innovative Capabilities through Effective Practical Training}

Due to the nature of the business and the financing resources of customers, supply chain finance presents diversified products. Financial teams often need to tailor financial solutions to their customers. The entire team continuously improves its supply chain product policies, services, and specifications in its design financing program, and is able to innovate products according to market demand.

\section{Conclusion}

The establishment of the integrated service innovation service platform of supply chain finance will not only increase the financing capacity of core enterprises, but also serve all enterprises in the supply chain, overcome numerous problems, such as the high financing thresholds for enterprises under the traditional financial model, especially the financing threshold for SME financing, and few institutions for loan guarantees, the low quality of enterprises, the lack of collaterals, the shortage of qualified personnel, and the constraints on bank control costs. With the establishment of the integrated service innovation service platform of supply chain finance, the enterprise operates according to the supply chain, and mobilizes resources such as inventory, prepayments, and accounts receivable of all enterprises in the supply chain to form a closed loop of logistics, information and capital flow as a way to increase its value.

\section{References}

[1] Risk-return optimization with different risk-aggregation strategies [J]. Stan Uryasev, Ursula A. 
Theiler, Gaia Serraino. The Journal of Risk Finance. 2010 (2)

[2] Coordination contracts in the presence of positive inventory financing costs [J]. Chang Hwan Lee, Byong-Duk Rhee. International Journal of Production Economics. 2009 (2)

[3] A Stochastic Inventory Model with Trade Credit [J]. Diwakar Gupta, Lei Wang. Manufacturing \& Service Operations Management. 2009 (1)

[4] The Exploitation of Relationships in Financial Distress: The Case of Trade Credit [J]. Benjamin S.Wilner. The Journal of Finance. 2007 (1)

[5] Small and medium-size enterprises: Access to finance as a growth constraint [J]. Thorsten Beck, Asli Demirguc-Kunt. Journal of Banking and Finance. 2006 (11) 